\title{
Pemanfaatan Ekstrak Kulit Buah Delima (Punica granatum L.) dalam Formulasi Sediaan Lip Balm
}

\section{The Utilization of Pomegranate (Punica granatum L.) Rind Extract in Lip Balm Dosage Form Formulation}

Penulis

Afiliasi

\section{Nazliniwaty ${ }^{1 *}$, Lia Laila ${ }^{1}$, dan Mega Wahyuni ${ }^{1}$}

${ }^{1}$ Departemen Teknologi Farmasi, Fakultas Farmasi, Universitas Sumatera Utara, Medan 20155, Indonesia *Email: nazliniwaty@usu.ac.id

\section{Kata Kunci \\ $\Rightarrow$ Ekstrak \\ O Kelembaban \\ - Kulit buah delima \\ L Lip balm \\ - Maserasi \\ Keywords \\ $\rightarrow$ Extract, \\ - Moisture \\ - Pomegranate rind \\ L Lip balm \\ O Maceration}

Diterima 15 April 2019

Direvisi 27 September 2019

Disetujui 7 Oktober 2019

*Penulis Koresponding Nazliniwaty email: nazliniwaty@usu.ac.id

\section{ABSTRAK}

Lip balm merupakan pelembab yang berfungsi untuk melembabkan bibir agar tidak mudah kering dan pecah-pecah. Kulit delima kaya akan flavonoid, asam fenolat, dan tanin yang berkhasiat sebagai antioksidan. Tujuan penelitian ini adalah untuk memformulasi sediaan pelembab bibir menggunakan ekstrak kulit buah delima dan menentukan waktu yang dibutuhkan untuk memberikan efek melembabkan. Kulit buah delima dimaserasi menggunakan pelarut etanol $96 \%$ dan dipekatkan dengan rotary evaporator. Ekstrak kulit buah delima dengan konsentrasi 2,$5 ; 5 ; 7,5$; dan 10\%, diformulasikan dalam dasar lip balm. Pengujian terhadap sediaan lip balm meliputi uji homogenitas, pengukuran $\mathrm{pH}$, uji iritasi dan uji stabilitas sediaan dengan parameter seperti bau, warna dan $\mathrm{pH}$ selama penyimpanan 12 minggu. Pengujian kemampuan sediaan untuk melembabkan menggunakan alat pemeriksa kelembaban dalam perangkat skin analyzer selama perawatan 4 minggu. Hasil penelitian diperoleh bahwa semua sediaan lip balm homogen, memiliki pH 5,6-6,1 stabil selama penyimpanan 12 minggu, dan tidak mengiritasi. Sediaan lip balm ekstrak kulit buah delima dengan konsentrasi $10 \%$ dapat memberikan efek melembabkan bibir paling baik yang mampu memulihkan kulit bibir setelah 4 minggu pemakaian.

\section{ABSTRACT}

Lip balm or lip ointment is a substantial wax spread on the lips to prevent the lips from dryness and chapped. The pomegranate rind is abundant in flavonoids, phenolic acids, and tannins which are having antioxidant properties. The purpose of this research was to formulate lip balm using pomegranate rind extract and to evaluate the moisturizing effect of pomegranate lip balm. The pomegranate rind was extracted using the maceration method with $96 \%$ ethanol as the solvent. Pomegranate rind extract was used with concentrations of $2.5,5,7.5$, and $10 \%$ in the lip balm base. The evaluation of the lip balm included homogeneity, $\mathrm{pH}$ measurement, irritation test and stability test of the lip balm with parameters of odour, colour and $\mathrm{pH}$ during 12 weeks of storage. The moisturizing effect was evaluated using moisture checker in the skin analyzer device during 4 weeks treatment. The results showed that all lip balm preparations were homogenous, with $\mathrm{pH}$ of 5.6-6.1, and were stable during the storage for 12 weeks. The lip balm with 10\% pomegranate rind extract gave the best effect to moisturize the lips by restoring the skin of the lips after 4 weeks. All formula of pomegranate lip balms showed no irritation effect to the skin. It can be concluded that the extract of pomegranate rind can be formulated in the lip balm dosage form with the concentration of pomegranate rind extract of $10 \%$ is able to give moisturizing effect to the lips after 4 weeks treatment. 


\section{PENDAHULUAN}

Kulit buah delima kaya akan flavonoid, asam fenolat, tanin, antosianidin, asam ellagat, kuersetin, asam galat, katekin, dan vitamin $\mathrm{C}$ yang mempunyai khasiat sebagai antioksidan. Kulit delima tidak hanya bermanfaat untuk mengatasi berbagai gangguan atau keluhan kesehatan, tetapi juga memiliki manfaat untuk merawat kecantikan kulit (Oci \& Dewi 2014). Antioksidan berfungsi mengatasi atau menetralisasi radikal bebas sehingga diharapkan dengan pemakaian produk yang mengandung antioksidan dapat menghambat dan mencegah terjadinya kerusakan tubuh. Bila jumlah antioksidan dalam tubuh tidak mencukupi, maka daya tahan tubuh akan menurun dan terjadi proses penuaan dini. Sehingga untuk dapat menangkal radikal bebas diperlukan ketersediaan antioksidan yang optimal dalam tubuh (Kurniati 2011).

Bibir merupakan bagian wajah yang sensitif, tidak memiliki pelindung. Oleh karena itu, bibir bisa menjadi kering dan pecah-pecah bila terpapar dengan udara panas ataupun dingin yang berlebihan. Selain tidak enak dipandang, bibir yang pecah-pecah juga menimbulkan rasa nyeri dan tidak nyaman (Muliyawan \& Suriana 2013). Salah satu manfaat produk kosmetik adalah untuk melindungi kulit karena bahan yang terkandung di dalamnya, sehingga dapat mempengaruhi fungsi biologis kulit. Beberapa ekstrak tumbuhan dan antioksidan yang diperoleh dari sumber alam mampu mencegah penuaan dan dapat meningkatkan kesehatan kulit (Pareetha \& Karthika 2009).

Selain lipstik dan lip gloss kosmetik bibir yang sering digunakan wanita adalah lip balm. Penggunaan lip balm berbeda dengan lipstik dan lip gloss. Penggunaan lip balm bertujuan lebih kepada perawatan bibir daripada untuk tujuan riasan yaitu untuk melindungi dan menjaga kelembaban bibir. Secara umum, lip balm mengandung zat pelembab dan vitamin yang dapat memproteksi bibir (Muliyawan \& Suriana 2013). Lip balm atau salep bibir adalah lilin substansi dioleskan pada bibir yang digunakan untuk menjaga bibir agar tidak mudah kering dan pecah-pecah. Biasanya lip balm digunakan untuk bibir yang membutuhkan proteksi, umpamanya pada keadaan udara dingin dengan kelembaban yang rendah dan untuk mencegah penguapan air pada cuaca yang panas. Lip balm merupakan sediaan kosmetik yang dibuat dengan basis yang sama dengan basis lipstik (Ratih 2014).

Sediaan lip balm dapat mengandung bahan aktif yang bertujuan untuk melindungi bibir dari cuaca ekstrim maupun panas matahari. Bahan aktif yang ditambahkan dalam sediaan lip balm dapat menggunakan bahan alami dari alam maupun senyawa kimia murni. Bahan alam memiliki keuntungan dengan minimnya efek samping yang ditimbulkan untuk penggunaan jangka panjang. Sehingga bahan alam saat ini menjadi primadona dalam formulasi sediaan kosmetik, termasuk dalam sediaan lip balm (Kadu et al. 2015).

Berdasarkan khasiat yang dimiliki oleh kulit buah delima maka peneliti mencoba melakukan formulasi dan menguji kemampuan melindungi dan memperbaiki bibir dari ekstrak etanol kulit buah delima dalam sediaan lip balm.

\section{METODE}

Penelitian ini meliputi pembuatan sediaan lip balm menggunakan ekstrak kulit buah delima dengan konsentrasi 2,$5 ; 5 ; 7,5$; dan $10 \%$. Pemeriksaan mutu fisik sediaan meliputi uji homogenitas, uji stabilitas, pengukuran $\mathrm{pH}$, uji iritasi terhadap kulit, dan pengujian kemampuan sediaan untuk melembabkan bibir dengan menggunakan alat pemeriksa kelembaban yang terdapat pada perangkat skin analyzer Aramo SG.

\section{Alat-Alat}

Alat-alat yang digunakan dalam penelitian meliputi: penangas air, spatula, kaca objek, cawan penguap, wadah lipstik, $\mathrm{pH}$ meter (Wilmaukee), neraca digital (Boeco Germany), skin analyzer Aramo SG (Aram Huvis Korea Ltd.) dan alat-alat gelas.

\section{Bahan}

Bahan yang digunakan dalam penelitian adalah kulit buah delima yang diperoleh dari daerah Berastagi, Sumatera Utara. Cera alba, oleum cacao, minyak jarak, propilen glikol, Tween 80, nipagin, dan Butylated Hydroxy Toluen (BHT) diperoleh dari Bratachem. Seluruh bahan kimia yang digunakan memiliki analytical grade dan digunakan tanpa pemurnian lebih lanjut.

\section{Pembuatan Ekstrak Etanol Kulit Buah Delima}

Sebanyak $500 \mathrm{~g}$ serbuk simplisia kulit buah delima direndam dengan penyari etanol $96 \%$ sebanyak 3,75 liter. Sampel dibiarkan selama 5 hari dengan dilakukan pengadukan sehari sekali. Setelah 5 hari, sampel disaring dan diperas. Ampas ditambah dengan cairan penyari sebanyak 1,25 liter, diaduk dan diperas sehingga hasil maserat sebanyak 5 L. Hasil maserat diuapkan dengan rotary evaporator hingga diperoleh ekstrak kulit buah delima yang kental (Ditjen POM 1979). 
Tabel 1. Formula Lip Balm dengan Ekstrak Kulit Buah Delima

\begin{tabular}{lccccc}
\hline \multirow{2}{*}{ Bahan } & \multicolumn{5}{c}{ Formula (g) } \\
\cline { 2 - 6 } & F0 & F1 & F2 & F3 & F4 \\
\hline Ekstrak Kulit Buah Delima & - & 0,25 & 0,5 & 0,75 & 1 \\
Propilen glikol & 0,5 & 0,5 & 0,5 & 0,5 & 0,5 \\
Cera alba & 2,2 & 2,2 & 2,2 & 2,2 & 2,2 \\
Minyak jarak & 1,5 & 1,5 & 1,5 & 1,5 & 1,5 \\
Tween 80 & 0,2 & 0,2 & 0,2 & 0,2 & 0,2 \\
Nipagin & 0,02 & 0,02 & 0,02 & 0,02 & 0,02 \\
BHT & 0,005 & 0,005 & 0,005 & 0,005 & 0,005 \\
Oleum cacao & 10 & 10 & 10 & 10 & 10 \\
\hline
\end{tabular}

\section{Pembuatan Lip Balm}

Pembuatan lip balm mengikuti formula dasar untuk lip balm dengan sedikit modifikasi seperti yang tertera pada Tabel 1. Oleum cacao dan cera alba dilelehkan dalam cawan yang terpisah. Lalu dimasukkan lelehan cera alba ke dalam basis oleum cacao, diaduk hingga homogen, kemudian dimasukkan secara perlahan minyak jarak, propilen glikol, nipagin dan BHT sambil terus diaduk dan dipanaskan. Kemudian sedikit demi sedikit ditambahkan ekstrak yang telah bercampur dengan Tween 80. Cawan diangkat dari atas penangas, selagi campuran cair dimasukkan ke dalam wadah lip balm (Ditjen POM 1985).

\section{Evaluasi Sediaan Lip Balm}

Evaluasi sediaan lip balm meliputi uji homogenitas; stabilitas secara organoleptis dan pengukuran $\mathrm{pH}$; iritasi dan kemampuan melembabkan bibir.

\section{Pengujian homogenitas}

Uji homogenitas dilakukan dengan menggunakan kaca objek. Sejumlah sampel dioleskan di atas kaca objek kemudian ditutup dan ditekan dengan kaca objek yang lain, kemudian diamati homogenitas dari sampel lip balm.

\section{Pengujian stabilitas}

Uji stabilitas dilakukan dengan mengamati bentuk, warna dan bau secara organoleptis juga dengan mengukur $\mathrm{pH}$ sediaan menggunakan $\mathrm{pH}$ meter (Wilmaukee) selama 12 minggu pada suhu kamar (Vishwakarma et al. 2011).

\section{Pengujian Iritasi}

Uji iritasi terhadap kulit dilakukan terhadap 10 orang panelis dengan cara mengoleskan sediaan lip balm pada kulit lengan bawah bagian dalam selama 2 hari berturut-turut (Tranggono \& Latifah 2007).

\section{Pengujian Efek Melembabkan Bibir}

Pengujian kemampuan sediaan untuk melembabkan bibir dilakukan dengan menggunakan pemeriksa kelembaban yang terdapat pada alat skin analyzer Aramo SG (Aramo 2012). Bibir sukarelawan diukur kadar airnya sebelum diberikan perlakuan (ko). Kemudian sukarelawan menggunakan lip balm sekali sehari selama 4 minggu dan setiap minggu diukur kadar airnya (kn). Kadar air yang diperoleh dicatat kemudian dihitung persentase peningkatan kadar air dengan rumus:

Peningkatan kadar air $=[(\mathrm{kn}-\mathrm{ko}) / \mathrm{ko}] \times 100 \%$

dimana:

ko = kadar air bibir mula-mula sebelum perlakuan

$\mathrm{kn}=$ kadar air bibir pada tiap minggu setelah perlakuan

\section{HASIL DAN PEMBAHASAN \\ Hasil Ekstraksi}

Hasil ekstrak kulit buah delima yang diekstraksi dengan menggunakan pelarut etanol secara maserasi yaitu sebanyak $98,65 \mathrm{~g}(19,73 \%$ dari total serbuk simplisia yang digunakan) dengan warna coklat kehitaman.

\section{Sediaan Lip Balm Ekstrak Kulit Buah Delima}

Sediaan lip balm ekstrak kulit buah delima 2,5\%, $5 \%, 7,5 \%$ dan $10 \%$ umumnya berwarna coklat. Semakin tinggi konsentrasi kulit buah delima semakin coklat warna lip balm yang dihasilkan sedangkan lip balm blanko berwarna putih seperti yang terlihat pada Gambar 1. 


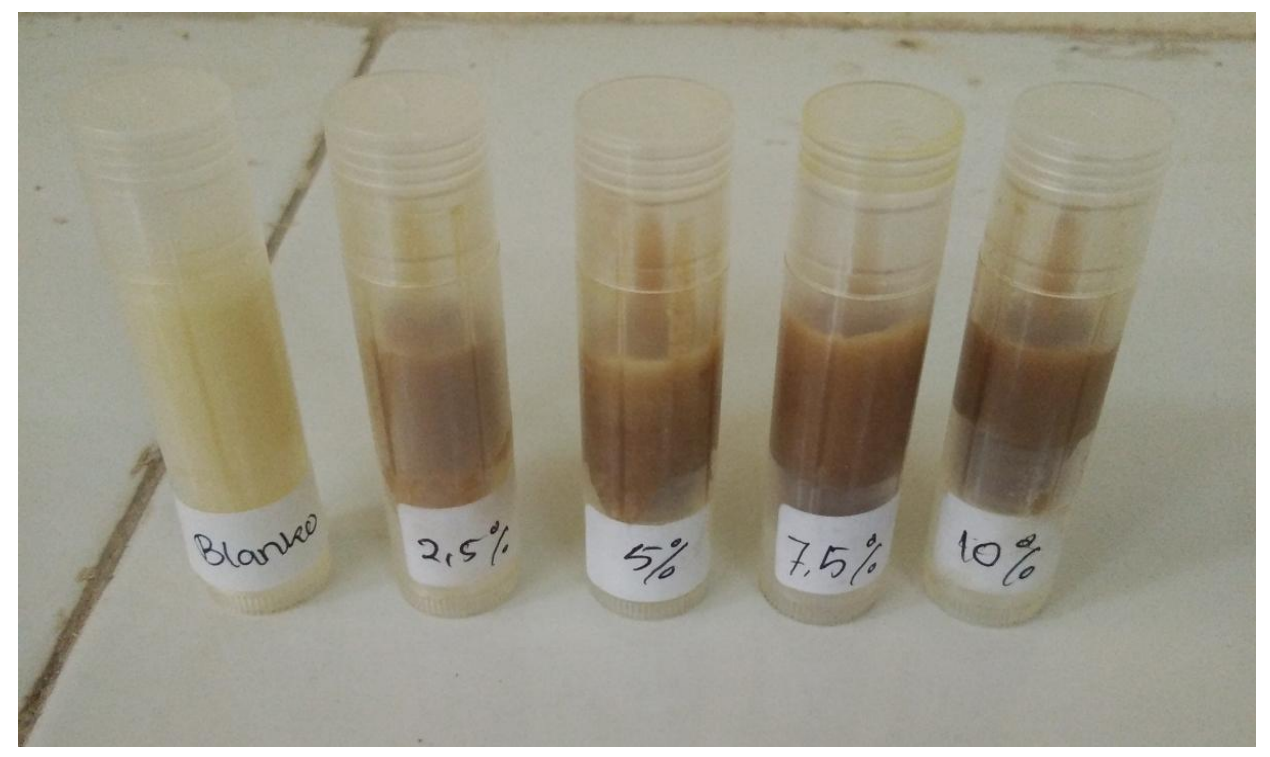

Gambar 1. Sediaan lip balm blanko dan yang mengandung ekstrak kulit buah delima

Tabel 2. Data pengukuran $\mathrm{pH}$ sediaan lip balm pada penyimpanan di suhu kamar selama 12 minggu

\begin{tabular}{cccccc}
\hline \multirow{2}{*}{ Formula } & \multicolumn{5}{c}{ Lama Pengamatan (Minggu) } \\
\cline { 2 - 6 } & $\mathbf{0}$ & $\mathbf{1}$ & $\mathbf{2}$ & $\mathbf{3}$ & $\mathbf{4}$ \\
\hline F0 & 6,1 & 6,1 & 6,2 & 6,1 & 6,1 \\
F1 & 6,0 & 6,0 & 6,1 & 6,1 & 6,1 \\
F2 & 5,9 & 5,9 & 6,0 & 5,9 & 5,9 \\
F3 & 5,8 & 5,8 & 5,7 & 5,7 & 5,7 \\
F4 & 5,7 & 5,7 & 5,7 & 5,6 & 5,6 \\
\hline
\end{tabular}

\section{Pemeriksaan Homogenitas}

Hasil pemeriksaan homogenitas terhadap sediaan lip balm ekstrak kulit buah delima dengan konsentrasi $2,5 \%, 5 \%, 7,5 \%, 10 \%$ adalah homogen. Hal ini ditandai dengan warna yang seragam dan tidak adanya butirbutir kasar pada saat sediaan dioleskan pada kaca transparan.

\section{Hasil Pengamatan Stabilitas Sediaan Lip Balm}

Hasil pengamatan sediaan lip balm dari ekstrak kulit buah delima menunjukkan bahwa seluruh sediaan yang dibuat tetap stabil dalam penyimpanan pada suhu kamar selama 12 minggu pengamatan dengan tidak menunjukkan perubahan pada bentuk, warna dan bau. Hasil penentuan $\mathrm{pH}$ sediaan lip balm ekstrak kulit buah delima menunjukkan bahwa sediaan lip balm yang menggunakan ekstrak kulit buah delima memiliki $\mathrm{pH}$ yaitu 5,7-6,0 dan $\mathrm{pH}$ sediaan lip balm tanpa ekstrak adalah 6,1. Pemeriksaan $\mathrm{pH}$ selama penyimpanan 12 minggu pada suhu kamar menunjukkan sediaan juga stabil secara kimia seperti yang tercantum pada Tabel 2. Sediaan lip balm yang stabil baik secara organoleptis dan kimia dapat mempertahankan penampilan maupun aktivitasnya dalam melembabkan bibir.

\section{Hasil Uji Iritasi}

Hasil pengujian menunjukkan bahwa semua panelis memberikan reaksi negatif terhadap parameter reaksi iritasi, sehingga sediaan lip balm yang diujikan dapat dikatakan tidak mengiritasi. Sediaan yang tidak mengiritasi merupakan sediaan yang diharapkan karena akan memberikan rasa aman bagi pengguna.

\section{Hasil Pemeriksaan Kadar Air (moisture)}

Pengukuran kadar air dilakukan dengan menggunakan alat pemeriksa kadar air yang terdapat dalam perangkat skin analyzer Aramo SG. Hasil pemeriksaan menunjukkan bahwa kadar air bibir semua kelompok sukarelawan sebelum pemakaian pelembab bibir adalah dehidrasi (kategori nilai 0-29) (Aramo 2012). Setelah pemakaian lip balm selama 4 minggu, semua sukarelawan mengalami peningkatan kadar air dari dehidrasi menjadi normal seperti yang ditunjukkan pada Gambar 2. Persentase peningkatan 


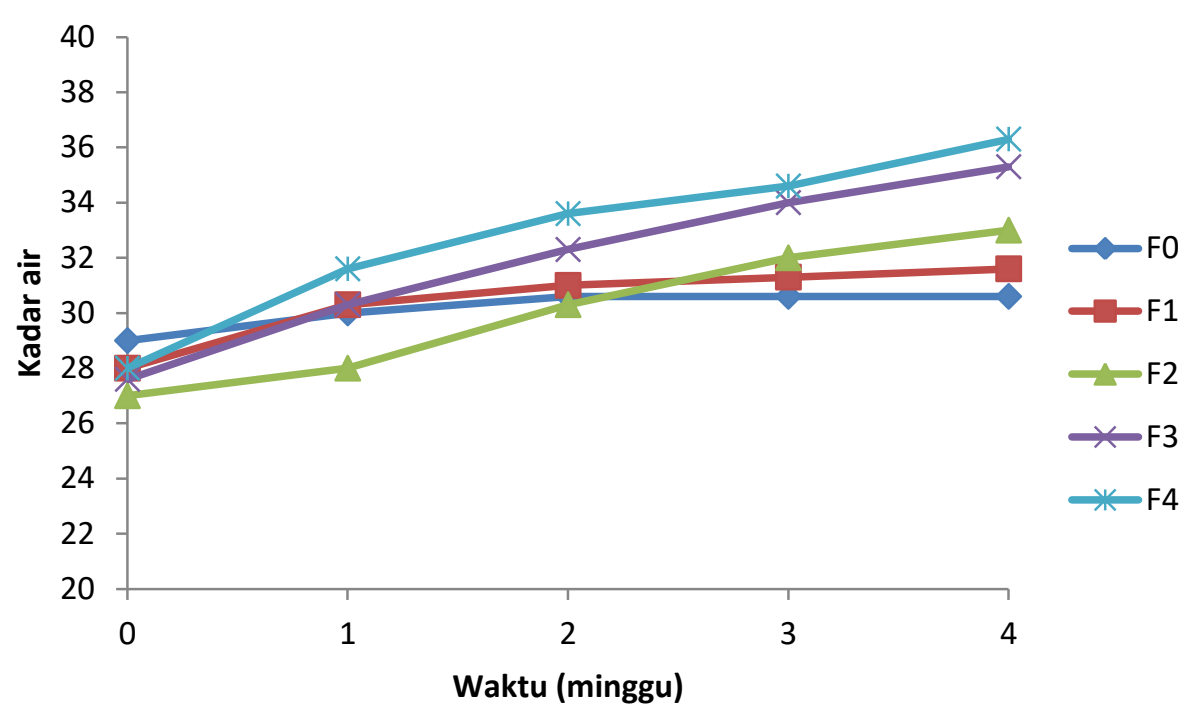

Gambar 2. Peningkatan kadar air pada bibir dengan penggunaan lip balm, $\mathrm{F} 0=$ lip balm tanpa ekstrak, $\mathrm{F} 1=$ lip balm dengan 2,5\% ekstrak kulit buah delima, $\mathrm{F} 2=$ lip balm dengan $5 \%$ ekstrak kulit buah delima, F3= lip balm dengan 7,5\% ekstrak kulit buah delima, F4= lip balm dengan 10\% ekstrak kulit buah delima.

kadar air bibir dengan pemakaian sediaan F0, F1, F2 dan F3 masing-masing adalah $5,7 \% ; 13,1 \% ; 22,2 \%$ dan $27,7 \%$. Persentase peningkatan kadar air bibir paling tinggi ditunjukkan oleh kelompok sukarelawan dengan perawatan menggunakan sediaan $\mathrm{F} 4$ yang mengandung konsentrasi ekstrak $10 \%$ yaitu sebesar $29,8 \%$.

Data dianalisis dengan menggunakan uji non parametrik Kruskal Wallis (Khairunnisa et al. 2012). Hasil analisis statistik dari pengukuran kadar air menunjukkan tidak adanya perbedaan yang signifikan antar formula setelah pemakaian lip balm setiap minggu pengamatan. Akan tetapi setelah 4 minggu pemakaian lip balm, hasil statistik menunjukkan bahwa terdapat perbedaan peningkatan kadar air yang signifikan $(p \leq 0,05)$ antara blanko dengan semua formula lip balm ekstrak kulit buah delima. Namun antara formula F2 dengan F3 tidak terdapat perbedaan peningkatan kadar air yang signifikan, begitu pula antara formula F3 dan F4. Peningkatan kadar air pada bibir sejalan dengan peningkatan konsentrasi ekstrak kulit buah delima yang digunakan. Konsentrasi ekstrak yang semakin tinggi memberikan persentase peningkatan kadar air yang semakin besar yang artinya bibir akan semakin lembab. Bibir yang memiliki kelembaban yang tinggi akan lebih cenderung sulit untuk mengalami kerusakan seperti kering dan pecahpecah walaupun berada pada kondisi lingkungan yang ekstrim. Kemampuan lip balm dalam mempertahankan kelembaban didukung dengan adanya bahan-bahan yang terkandung di dalamnya. Sebagai bahan dasar pembuatan lip balm, cera alba, oleum cacao dan minyak, dalam penelitian ini minyak jarak, memiliki kemampuan dalam menahan penguapan air, dan ini merupakan salah satu faktor dalam aktivitas lip balm untuk mempertahankan kelembaban bibir (Harry \& Wilkison 1973). Seperti yang terlihat pada Gambar 1., kelompok yang menggunakan lip balm tanpa ekstrak juga menunjukkan peningkatan kadar air pada bibir walaupun tidak signifikan. Penggunaan bahan yang bersifat lemak khususnya yang mengandung lemak tak jenuh akan lebih mudah diserap oleh bibir (Kadu et. al. 2015). Ekstrak kulit buah delima yang ditambahkan ke dalam lip balm memiliki fungsi sebagai antioksidan alami yang dapat mempertahankan fungsi melembabkan dari lip balm yang telah diuji. Ekstrak kulit buah delima memiliki aktivitas antioksidan yang tinggi seperti yang telah dilaporkan oleh Singh et al. (2002). Aktivitas antioksidan ini didukung oleh kandungan senyawa yang terdapat di dalam kulit buah delima seperti flavonoid, tanin, antosianin, asam ellagat, punicalagin, punicalin, asam galagat, asam hidroksi sinamat, kuersetin, asam galat, dan katekin (Akhtar et al. 2015; Elfalleh et al. 2012). 


\section{SIMPULAN}

Ekstrak kulit buah delima dapat dimanfaatkan sebagai pelembab bibir dalam sediaan lip balm. Semakin tinggi konsentrasi ekstrak memberikan persentase peningkatan kadar air yang semakin tinggi dan dapat meningkatkan kadar air bibir dari dehidrasi menjadi normal.

\section{UCAPAN TERIMA KASIH}

Penulis mengucapkan terima kasih kepada Laboratorium Kosmetologi Fakultas Farmasi Universitas Sumatera Utara yang telah memberikan fasilitas untuk melakukan penelitian ini.

\section{DAFTAR PUSTAKA}

Akhtar S, Ismail T, Fraternale D, \& Sestili P. 2015. Pomegranate peel and peel extracts: Chemistry and food features. Food Chemistry. 174: 417-425

Aramo. 2012. Skin and Hair Diagnosis System. Seongnam (KR): Aram Huvis Korea Ltd.

Ditjen POM. 1979. Farmakope Indonesia. Edisi III. Jakarta (ID): Departemen Kesehatan Republik Indonesia.

Ditjen POM. 1985. Formularium Kosmetik Indonesia. Jakarta (ID): Departemen Kesehatan RI.

Elfalleh W, Hannachi $H$, Tlili N, Yahia $Y$, Nasri N, Ferchichi A. 2012. Total phenolic contents and antioxidant activities of pomegranate peel, seed, leaf and flower. Journal of Medicinal Plants Research. 6(32): 4724-4730.

Harry RG, Wilkinson JB. 1973. Harry's Cosmeticology, six ed. London: Leonard Hill books and Intertext publisher.
Kadu M, Vishwasrao S, Singh S. 2015. Review on Natural Lip Balm. International Journal Of Cosmetic Science. 5 (1): 1-7.

Khairunnisa, Husori DH, Tanjung HR. 2012. Statistika Farmasi: Aplikasi menggunakan SPSS. Medan (ID): USU Press.

Kurniati N. 2011. Uji Stabilitas Fisik dan Aktivitas Antioksidan Formula Krim Mengandung Ekstrak Kulit Buah Delima (Punica granatum L) [Skripsi]. Depok (ID): Universitas Indonesia.

Muliyawan D, Suriana N. 2013. A - Z Tentang Kosmetik. Jakarta (ID): PT. Elex Media Komputindo.

Oci YM, Dewi KK. 2014. Khasiat Ajaib Delima. Jakarta (ID): Padi.

Pareetha JP, Karthika K. 2009. Cosmeceuticals - An Evolution. International Journal of ChemTech Research. 1(4) : 0974-4290.

Ratih H. 2014. Formulasi Sediaan Lipbalm Minyak Bunga Kenanga (Cananga Oil) Sebagai Emolien [Skripsi]. Cimahi (ID): Universitas Jendral Achmad Yani.

Singh RP, Murthy KNC, Jayaprakasha GK. 2002. Studies on the Antioxidant Activity of Pomegranate (Punicagranatum) Peel and Seed Extracts Using in Vitro Models. International Journal Agriculture Food Chemistry. 50(1): 81-86.

Tranggono RI, Latifah F. 2007. Buku Pegangan IImu Pengetahuan Kosmetik. Jakarta (ID): PT.Gramedia Pusaka Utama.

Vishwakarma B, Dwivedi S, Dubey K, Joshi H. 2011. Formulation and Evaluation of Herbal Lipstick. International Journal of Drug Discovery and Herbal Research. 1(1): 18-19. 